\title{
Impacts of GHG emissions abatement measures on agricultural market and food security
}

Shinichiro Fujimori ( $\nabla$ sfujimori@athehost.env.kyoto-u.ac.jp )

Kyoto University https://orcid.org/0000-0001-7897-1796

\section{Wenchao Wu}

Center for Social and Environmental Systems Research, National Institute for Environmental Studies (NIES)

\section{Jonathan Doelman}

PBL

\section{Stefan Frank}

International Institute for Applied Systems Analysis

\section{Jordan Hristov}

European Commission, Joint Research Center

\section{Page Kyle}

Joint Global Change Research Institute, Pacific Northwest National Laboratory, College Park, Maryland

\section{Ronald Sands}

USDA Economic Research Service

\section{Willem-Jan van Zeist}

PBL https://orcid.org/0000-0002-6371-8509

\section{Petr Havlík}

International Institute for Applied Systems Analysis https://orcid.org/0000-0001-5551-5085

\section{Ignacio Pérez Domínguez}

European Commission, Joint Research Center

\section{Amarendra Sahoo}

European Commission, Joint Research Center

\section{Elke Stehfest}

PBL Netherlands Environmental Assessment Agency https://orcid.org/0000-0003-3016-2679

\section{Andrzej Tabeau}

Wageningen Economic Research

\section{Hugo Valin}

International Institute for Applied Systems Analysis https://orcid.org/0000-0002-0618-773X

\section{Hans van Meijl}

Wageningen University and Research Centre, Wageningen, Netherlands

\section{Tomoko Hasegawa}

Ritsumeikan University https://orcid.org/0000-0003-2456-5789 
Kiyoshi Takahashi

National Institute for Environmental Studies https://orcid.org/0000-0002-0163-545X

\section{Article}

Keywords: Agriculture Market Management, Forestry, Land-use, Greenhouse Gas Emissions Reduction, Non-CO2 Emissions, Bioenergy Production, Afforestation

Posted Date: January 15th, 2021

DOl: https://doi.org/10.21203/rs.3.rs-128167/v1

License: (c) (1) This work is licensed under a Creative Commons Attribution 4.0 International License. Read Full License

Version of Record: A version of this preprint was published at Nature Food on February 24th, 2022. See the published version at https://doi.org/10.1038/s43016-022-00464-4. 
1 Impacts of GHG emissions abatement measures on agricultural market and

2 food security

3

4 Abstract:

5 Agriculture, Forestry and Other Land-use (AFOLU) are thought to play a vital role in long-term GHG 6 emissions reduction, especially for their importance in non- $\mathrm{CO}_{2}$ emissions, bioenergy supply and

7 carbon sequestration realized by afforestation. Several studies have noted potential adverse impacts of

8 land-related emissions mitigation on food security, due to food price increases, but these studies have

9 not disaggregated the individual aspects of land-related emissions mitigation that impact food security.

10 Here, we show the extent to which three factors - non- $\mathrm{CO}_{2}$ emissions reduction, bioenergy production,

11 and afforestation - change the food security and agricultural market conditions under $2{ }^{\circ} \mathrm{C}$ climate

12 stabilization scenarios, using six global agro-economic models. The results show that afforestation,

13 often implemented in the models by imposing carbon prices on land carbon stocks, causes the largest

14 impacts on food security, followed by non- $\mathrm{CO}_{2}$ emissions policies, generally implemented as

15 emissions taxes. Respectively, these measures put an additional 41.9 and 26.7 million people at risk

16 of hunger in 2050. This study highlights the need for better coordination of emissions reduction and

17 agricultural market management policy.

\section{Introduction}

In meeting near- and long-term climate change mitigation goals (e.g., the Paris Agreement), the energy sector accounts for the majority of greenhouse gas (GHG) emissions in most nations, and is thus the target of most present-day emissions mitigation policies. However, Agriculture, Forestry and Other Land Use (AFOLU) account for $20-25 \%$ of global GHG emissions in $2010^{1}$ and cannot be ignored in the context of meeting ambitious long-term climate change mitigation targets. In addition to the baseline emissions quantities involved, the non-point-source nature of the emissions, combined with the relative lack of available technologies to eliminate emissions, make AFOLU emissions abatement especially difficult. This is in contrast to the energy sector, whose emissions can become net-zero or even net-negative if carbon removal technologies are used ${ }^{2}$.

The future emissions reduction potential in the AFOLU sector has been characterized in the literature as having relatively large emission reductions available at low cost, compared with other sectors $^{3,4,5}$. However, the emissions reduction potentials are understood to be limited, with full (100\%) removal not possible regardless of effort in many cases ${ }^{6}$. Moreover, Hasegawa et al. (2018) highlighted significant food security concerns associated with including AFOLU in climate change mitigation actions $^{7}$. The present study contributes to this discussion, by starting with the observation that there are three major channels by which AFOLU-focused climate change mitigation policy may exacerbate food security. One is promotion of large-scale bioenergy crop expansion; low-emissions scenarios in 
integrated assessment models (IAMs) have highlighted the potential importance of bioenergy, particularly bioenergy with carbon capture and storage (BECCS), for reducing costs and enabling deep system-wide emissions mitigation ${ }^{8,9,10}$. The consequent competition between food and bioenergy production can cause increased prices and reduced supplies of food crop commodities. Second, policies that price non- $\mathrm{CO}_{2}$ emissions can directly increase costs of food production and thus food commodity prices ${ }^{11,12}$. The third channel is afforestation policies, which incentivize a reduction in cropland supply.

While these secondary impacts of AFOLU emissions mitigation have been addressed in the literature $^{13,14}$, the present body of knowledge has not identified the relative importance of the factors that drive potential food security risk. Studies have focused on each element individually; for example, the direct impacts of non- $\mathrm{CO}_{2}$ emissions reductions ${ }^{15}$, or the implications of bioenergy expansion ${ }^{12}$. Afforestation has also been addressed individually, albeit for carbon sequestration potential, with less emphasis on food security issues ${ }^{16,17}$. However, the existing literature has not yet addressed the relative importance of these three factors for food security.

Here, we show the relative extent to which the above-mentioned three factors $\left(\mathrm{Non}-\mathrm{CO}_{2}\right.$ emissions reduction in the agricultural sector, afforestation, and energy crop expansion) change the food security and agricultural market conditions under climate mitigation scenarios. To decompose the three causes, we examine several scenarios that are consistent with limiting the global mean temperature increase to below $2^{\circ} \mathrm{C}$. To explore the uncertainty range, we employ six state-of-the-art global agro-economic models that represent agriculture and land-use systems, and their emissions; namely $\mathrm{AIM}^{18}$, CAPRI ${ }^{19}, \mathrm{FARM}^{20}, \mathrm{GCAM}^{21}, \mathrm{GLOBIOM}^{22}$, and IMAGE-MAGNET ${ }^{23}$. For the scenarios, the carbon prices, bioenergy production requirements, and forest area are harmonized where possible among the models. We found that the models' representations of non-CO2 emissions pricing were generally consistent, whereas the implementation of afforestation-related policies varied from one model to the next. We also employ a "hunger tool" which enables us to explore the number of people at risk of hunger ${ }^{7,24,25}$. The scenarios analyzed in this study assume the socioeconomic background of Shared Socioeconomic Pathways SSP2 26,27 , and for the climate policy scenarios, Representative Concentration Pathways (RCP) 2.6 equivalent carbon prices are applied, which are taken from the SSP database. See Method section more details and illustration for the overall research framework (Supplementary Figure 1).

\section{Results}

\section{Main indicators}

In the baseline scenarios, global average calorie availability over the upcoming decades continuously increases, mostly due to income growth in developing countries, reaching 3058 $\mathrm{kcal} /$ pers/d in 2050 (3013-3260 among the models; hereafter, ranges indicate the inter-model spread) 
(Figure 1a). Accordingly, the number of people at risk of hunger declines overtime, to 417.6 million (289.4-545.9) in 2050 (Figure 1b). This trend is consistent with the earlier studies ${ }^{7,13,28}$. The models' general agricultural producer price indices are projected to be almost constant over this timeframe, with a range of 0.95 to 1.26 in 2050 (Figure 1c). Price projection diversity across models has been observed in the earlier studies as well ${ }^{29}$. Agricultural technological improvement and demand increases are the main negative and positive drivers of prices, respectively, which tend to offset each other.

Under the climate change mitigation scenario to attain well below $2^{\circ} \mathrm{C}$ global mean temperature, there would be carbon (or GHG) pricing implicitly or explicitly which is fed into the models (see Supplementary Figure 2). Along with the carbon emissions price imposition (e.g. carbon tax), GHG emissions mitigation actions are carried out by the agricultural and land-use system, pushing up the production cost and land-rent, and agricultural commodity producer prices (Figure 1c). Consequently, calorie availability decreases by $119(32-163) \mathrm{kcal} / \mathrm{cap} / \mathrm{day}$, and the population at risk of hunger increases by 125.5 (28.6-155.4) million (Figure 1ab).

The decomposition of these adverse side effects of the climate mitigation actions in food security are driven by three causes that have been discussed earlier and additional risk of hunger are generated by $41.9,12.0$, and 26.7 million in 2050 (Figure 1 e) by afforestation, bioenergy and non- $\mathrm{CO}_{2}$ emissions, respectively (numbers are multi-model median). These can be mostly explained by average food consumption decrease (Figure 1d) and agricultural price increases (Figure 1f). For example, afforestation, bioenergy and non- $\mathrm{CO}_{2}$ emissions induce agricultural price increases by $18.1 \%, 1.3 \%$, and $11.7 \%$, respectively (numbers are multi-model median). While median clearly shows the magnitude of individual causes, there are certain model variations that can be interpreted as uncertainty. For example, afforestation effect on additional risk of hunger ranges from 10.9 to 90.3 million. These model variations would depend on the representation of the mitigation measures and model structure which are discussed in detail later. Given that there is model uncertainty, we carried out a sensitivity analysis to test whether a specific "extreme" model would lead this conclusion or not. This sensitivity analysis is conducted by withdrawing one model, and iterating for all models. The conclusion is that our results are not dependent on a specific model (Supplementary Figure 3). Also, analysis based on the four models with complete sets of scenarios show similar patterns (Supplementary Figure 5).

Note that models which have explicit energy and economy components within the model show non-agricultural and non-land-use related effects to some extent (e.g. income-loss associated with lowcarbon energy technologies). It would be smaller than others except for AIM/Hub which shows additional 29.0 million people become under the risk of hunger (Supplementary Figure 4). 

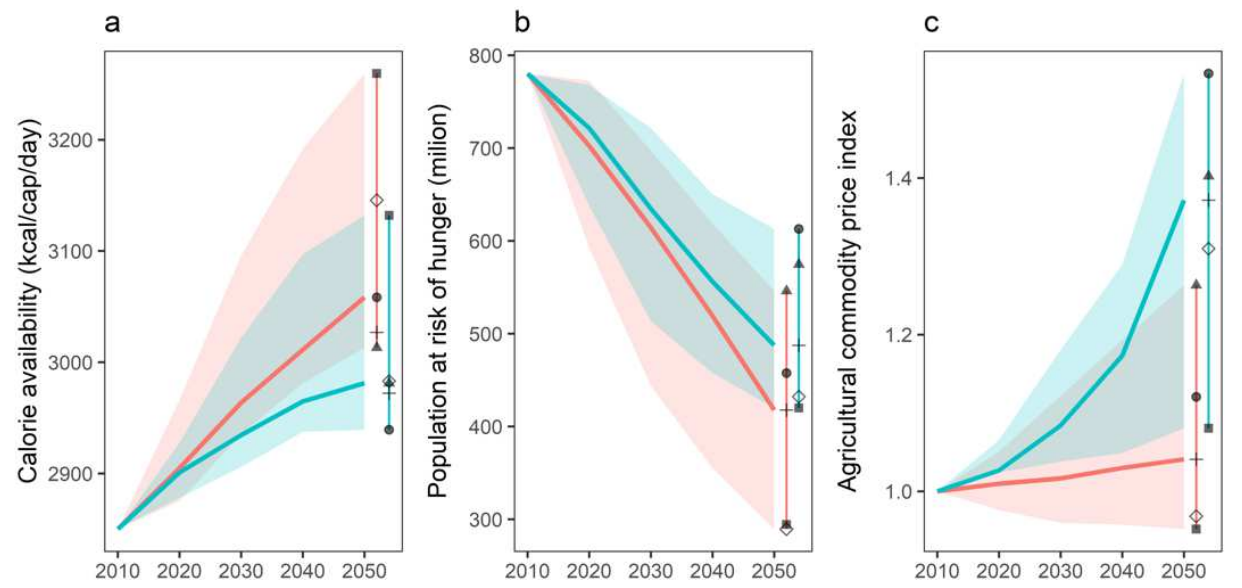

Climate policy

- Baseline

- Full mitigation

Model

- AlM/Hub

$\triangle$ CAPRI

$\triangle$ FARM
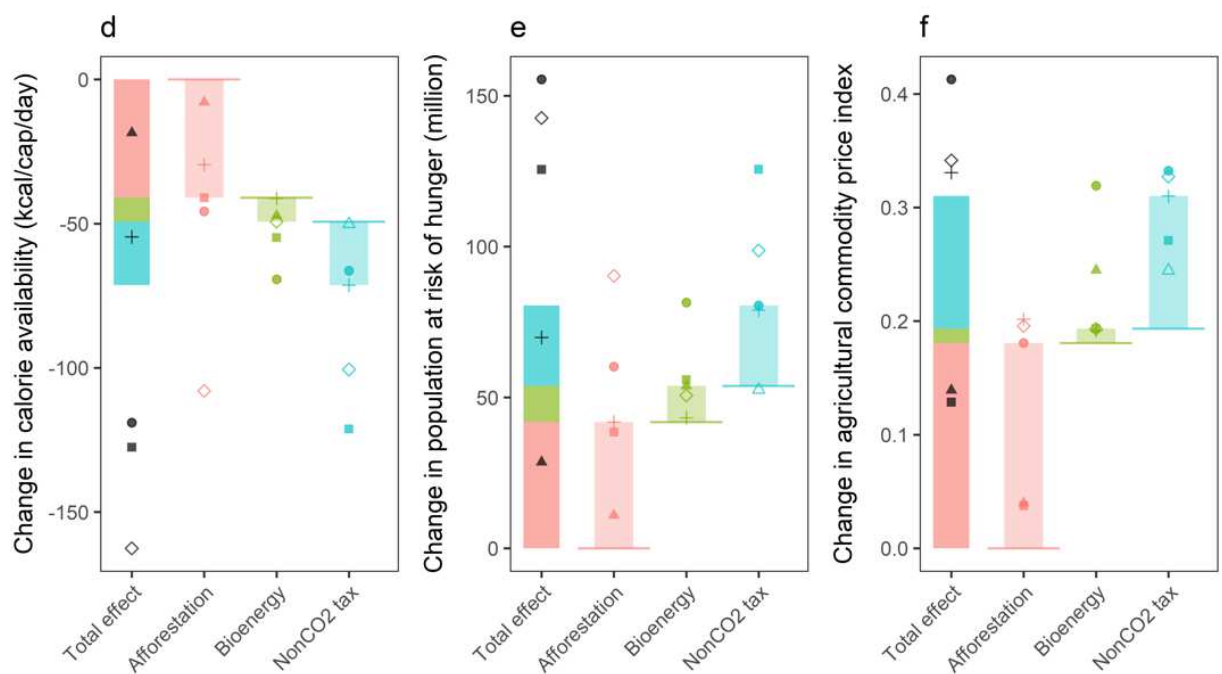

+ GCAM

- globiom

$\diamond$ MAGNET-IMAGE

Component

Afforestation

Bioenergy

NonCO2 tax

Figure 1 Calorie availability (a), population at risk of hunger (b), and agricultural commodity price

(c) in baseline and mitigation (full) scenarios, and the effects of each land-based mitigation measures on their change (def) for SSP2 (results based on four models with complete scenarios were shown in Supplementary Figure 5)

\section{Drivers of food price increases}

114 Afforestation for the purpose of sequestering carbon from the atmosphere to the terrestrial system is incentivized by carbon pricing on the carbon sink above- and below-ground. The $\mathrm{CO}_{2}$ emissions

116 drastically decreases in the mitigation scenarios (Figure 2a) and become negative 3.80 (0.20-13.74)

$117 \mathrm{Gt} \mathrm{CO}_{2}$ in 2050. Accordingly, forest area increases by $11.1 \%(1.7 \%-24.7 \%)$ in 2050 relative to 118 baseline scenarios and these forest area expansion put an additional land demand pressure on overall agricultural activities (Figure 2e). The land rent can also increase by pricing on land carbon sink and both factors would increase the average land rent by $366 \%$ in 2050 (from AIM/Hub model).

Non- $\mathrm{CO}_{2}$ emissions mitigation is the second largest contributor to the price increases associated with mitigation measures. There are basically two factors to increase the agricultural production prices. 
First, under a certain GHG emissions prices, $\mathrm{CH}_{4}$ and $\mathrm{N}_{2} \mathrm{O}$ abatement technologies are implemented, which simply add up the agricultural production cost particularly in livestock products (Supplementary Figure 6). Second, in contrast to $\mathrm{CO}_{2}$ emissions which can be negative value, non- $\mathrm{CO}_{2}$ are thought to be difficult completely gotten rid of and some potions such as $68.6 \%(56.5 \%-84.6 \%)$ remain as residual emissions (Figure $\mathbf{2 b c}$ ), which is slightly larger than existing literature but possibly due to the sectoral coverage ${ }^{30,31}$. This would become a penalty of carbon pricing (e.g. carbon tax imposition). Interestingly, the maximum emissions reductions almost reach under a certain carbon price which would imply that further higher carbon prices that are primarily determined by energy system side in IAMs would increase the penalty of the carbon prices from that point (Figure $\mathbf{2 h}$ ).

Finally, the energy purpose biomass crop can compete with current food crops which pushes the land demand pressure on the land market. Current model estimates show the bioenergy crop area is 196 (62-494) million ha in 2050 under the full mitigation policy, which accounts for $11.7 \%$ of the current cropland area (Figure 2d).

Although afforestation and bioenergy both need large amount of land and therefore might compete with land for food production, results suggest that the effect of afforestation is larger than bioenergy. That's because afforestation requires more land than bioenergy, possibly due to the higher carbon sink capacity of bioenergy crops particularly combined with CCS. In the bioenergy scenario, bioenergy land increase by 190 (74-690) million ha in 2050, along with even small increase of cropland (the median change is positive 40 million ha, with a range from negative 59 to positive 86); whereas in afforestation scenario, forest area increases by 420 (71-895) million ha, with the decrease of cropland by 103 (42-178) million ha. While bioenergy volume is determined by energy system, afforestation area can expand without ceiling, which would be also another potential reason ${ }^{32}$.

The above mentioned three drivers are also compatible with the carbon prices which clearly show the correlation while there are some inter-model variations in the carbon price assumptions (Figure $\mathbf{2 f g h}$ ). Food consumption, agricultural prices and risk of hunger similarly show the clear responses to carbon prices (Supplementary Figure 7). 

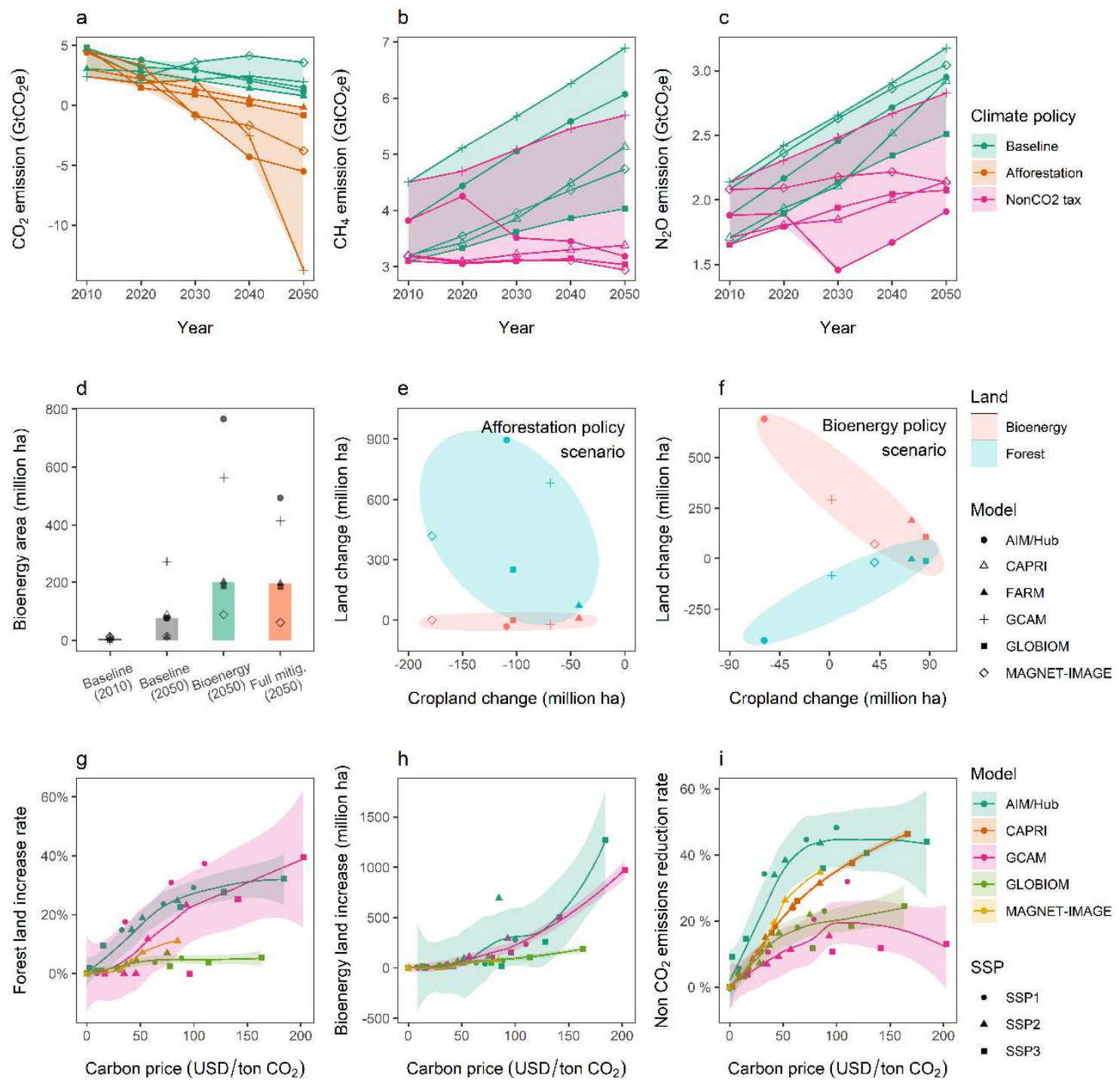

Figure 2 Main drivers of mitigation effects for SSP2. Panel ab and $\mathbf{c}$ present $\mathrm{CO}_{2}, \mathrm{CH}_{4}$ and $\mathrm{N}_{2} \mathrm{O}$ emissions from AFOLU sector. Panel d shows bioenergy land in each scenario. Panel $\mathbf{e}$ and $\mathbf{f}$ illustrate the relationship between cropland area, and bioenergy and forest area changes. Panel ghi show the relationship between carbon price and forest area, bioenergy area and non- $\mathrm{CO}_{2}$ emissions reduction rates (Non- $\mathrm{CO}_{2}$ emissions is $\mathrm{CO}_{2}$ equivalent value using GWP2100 in AR5).

\section{Regional implications}

The global trend in terms of the composition shares of three mitigation measures in risk of hunger is in principle similar across regions. Risk of hunger in most regions except for Sub-Saharan Africa is projected to decrease overtime mainly driven by income growth as global results, which might not be the case for short-term due to COVID-19. China and India have relatively high-income growth and thus the risk of hunger rapidly decreases, which are 43.6 (21.4-70.7) and $79.0(22.8-100.0)$ million, 
164 million in 2010 to 154.3 (67.6-175.6) million in 2050 despite of population growth; whereas the share 165 in the world would increase from $21.1 \%$ in 2010 to $29.3 \%(23.0 \%-40.0 \%)$ in 2050 . The relative 166 change ratios associated with total mitigation measures would be more or less similar across regions 167 and the absolute population changes would depend on the baseline projection except for African region. 168 Consequently, the African region can be the largest and incremental population at risk of hunger in 1692050 is $35.3(12.0-69.5)$ million (Figure 3a). The decomposition of three mitigation measures differ 170 between Asian and African regions. Asian regions would have relatively high impacts in non- $\mathrm{CO}_{2}$ emissions whereas African regions show large share in afforestation. Income could be an explanatory variable for this difference. Asia has higher income per capita than Africa (Supplementary Figure 8) which leads larger meat consumption and livestock oriented non- $\mathrm{CO}_{2}$ emissions (Supplementary Figure 9 and Supplementary Figure 10). Another possibility is from the context of land rent, which is basically low in Africa than Asia and same carbon price can have large impact on Africa. More detailed regional results are shown in Supplementary Figure 12. Note that Asian rice field area is relatively larger which may lead larger $\mathrm{CH}_{4}$ emissions, but it seems not the major factor for the above-mentioned price changes. (Supplementary Figure 11).

179 

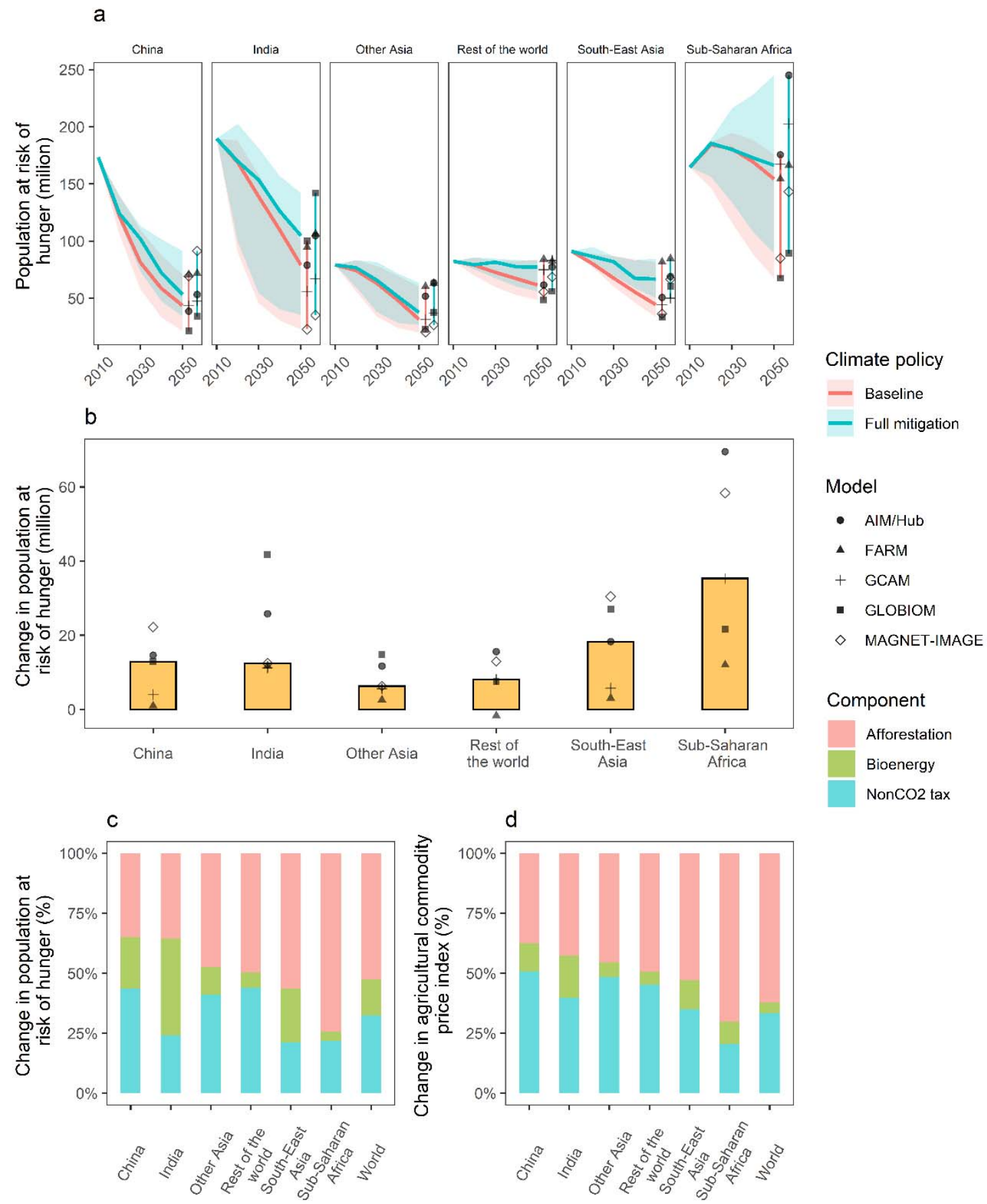

182 Figure 3 Regional effects of each land-based mitigation measures on risk of hunger and food price for 183 SSP2. panel a shows the population at risk of hunger over the period by regions and panel $\mathbf{b}$ shows 184 changes in risk of hunger of mitigation scenario relative to baseline scenario. Panel cd show percentage 185 share for each cause of changes in risk of hunger and agricultural price index. (see Supplementary 186 Table 1 for regional definition) 


\section{Socioeconomic variations}

The socioeconomic development is one of the key elements that determine future agricultural market and food security condition. We further carried out a sensitivity test under different

191 socioeconomic assumptions namely SSP1 and SSP3 which have large variety in the future prospect (e.g. low population and high economic growth in SSP1, and high population and low economic development in SSP3) ${ }^{33}$. In baseline scenarios, population at risk of hunger decreases faster in SSP1 as compared with SSP2 due to the rapid economic development particularly in current low-income countries. Meanwhile, SSP3 shows opposite to SSP1's direction which increases or stable in risk of hunger over the next couple of decades (Figure 4a). The response to the climate mitigation policies differ and the risk of hunger in SSP1 and SSP3 increases by 61.1 (12.3-73.9) and 359.3 (264.7-557.3)

198 million compared with baseline scenarios respectively in 2050. This could be partly due to the differences in baseline hunger perspectives, but more importantly, the risk of hunger in SSP3 should be more sensitive than others to the same carbon price because the basic income is low and thus, hit the poor more severely. The percentage changes give clearer characteristics of SSPs; namely $28.4 \%$ $(4.2 \%-47.9 \%)$ and $46.1 \%(36.0 \%-66.2 \%)$ in SSP1 and SSP3 respectively. We can also see this behavior from the price changes in Supplementary Figure 6.

In contrast to the total effects of climate mitigation, the decomposition of three causes show similar trend in all SSPs (Figure 4def). In SSP1, afforestation, bioenergy and non- $\mathrm{CO}_{2}$ induce additional risk of hunger 37.6, 3.0, and 17.5 million (model median) while in SSP3 they are 132.7, 49.7 and 74.4 million (model median), respectively in 2050. This would imply that the robustness of our findings in SSP2 shown earlier. It can also be interpreted that regardless of future socioeconomic conditions, the afforestation and non- $\mathrm{CO}_{2}$ would be the main factors and thus policymakers would put more attention than bioenergy. 

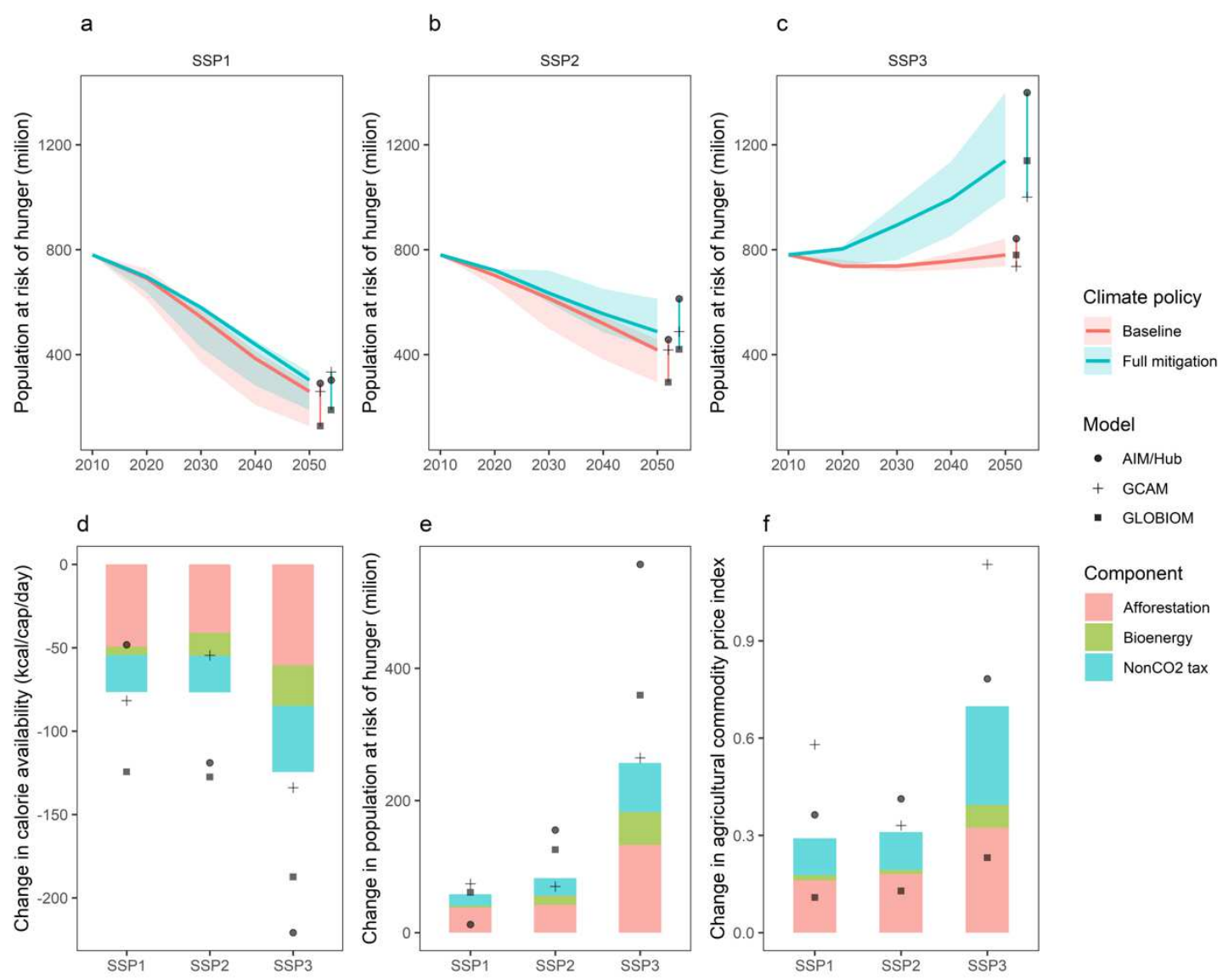

- GLOBIOM

Component

Afforestation

Bioenergy

NonCO2 tax

Figure 4. SSP variations in global population at risk of hunger (abc) and change in food consumption, population at risk of hunger and agricultural price index in three SSPs in 2050 (def).

\section{Discussions and conclusions}

We have identified the three main causes of food security and agricultural changes associated with climate change mitigation measures; namely afforestation, bioenergy expansion and non- $\mathrm{CO}_{2}$ emissions abatement. Afforestation turned out to be the primary driver of making adverse-side effects on food security followed by non- $\mathrm{CO}_{2}$. We confirm this similar implication under different socioeconomic assumptions with multiple global agricultural economic models. We further demonstrate that specific extreme models do not lead our conclusion. Regionally, Sub-Saharan Africa is most vulnerable to these shocks. Our results indicate the complexity and challenges in the AFOLU sector's climate mitigation policy from multiple angles.

We summarize the logical chains of the causes and effects of climate change mitigation measures and agricultural price increases in Figure 5 which we should think how to cut off any chains linking to the cost increases for each. Most stringent climate stabilization scenarios heavily rely on negative emissions technologies such as afforestation and BECCS, and non- $\mathrm{CO}_{2}$ emissions would be more important under low or net zero emissions conditions ${ }^{4,}{ }^{34}$. The carbon pricing on land carbon stock 
generally increases the land rent and motivate land-owners to plant trees. Higher the carbon price and 230 productivity, the stronger this incentive is. This afforestation induces the cropland decreases and 231 production cost upwards. Bioenergy increases can trigger the similar effects. In this case, energy crop 232 land is the competitors for food crops. The non- $\mathrm{CO}_{2}$ effect has a slightly different way to increase the cost, which directly hit the food crop production by the technological implementation of non- $\mathrm{CO}_{2}$ emissions abatement and carbon price imposition to the residual emissions. Once climate policy would give incentives to these measures, it might be difficult to cut-off the left arrows in Figure 5. One possibility to prevent this situation would be transforming the societal structure completely (e.g. reducing energy demand drastically ${ }^{35}$ and lifestyle change ${ }^{36}$ ). Although there are possibilities that the society move forward to such directions, it would be too optimistic to only bet on that.

The second left arrows in Figure 5 would be able to be somehow cut off by policy. For example, even if large scale afforestation and bioenergy expansion occur, land rent could be controlled by policy. To prevent those land demands invading cropland for food, the strong regulation on the cropland for food cultivation might also work. Note that without the carbon pricing on land sink, there would be strong incentives to cultivate the land for gaining negative emissions and thus there must be some policies specifically to deal with non-food land demand ${ }^{37,38}$. Regarding the right-hand side arrows linking from secondary effects to the production costs in Figure 5, policy roles would again be crucial, but technology can also change the situation. As current agricultural policy conditions in many countries, there are more or less supports for agricultural production directly or indirectly. This would imply that the production cost increase could be managed by such policies similarly. For example, the subsidy would be often used for the agricultural sector, and in this case, subsidy for the incremental cost to off-set the price increases could be a possible solution. Then, the issue of this policy would be the scale of the market distortion. The current estimates show the cost increases by around $30 \%$ relative to baseline. If we aim to subsidize these cost increases, how to get the tax revenue as a source of subsidy and getting social acceptance would be an issue. Note that carbon tax revenue might be a right candidate for this purpose ${ }^{39}$. Technological progress in non- $\mathrm{CO}_{2}$ emissions reduction and bioenergy yield would mitigate the agricultural cost increases. While it is essential to encourage research and development in those technologies, we should keep in mind that technological progress is essentially uncertain.

Besides the supply side management, there can be demand-side transition to mitigate the adverse side effects such as dietary shift reducing meat consumption ${ }^{40,41}$, changing distribution of food for the poor people and implementing subsidy for consumption ${ }^{14,42}$. In any cases, abovementioned measures may not be effective with a single independent action. We would need holistic approaches for food security under deep decarbonization transition. Trade would be thought as one of the measures to fill the gap between supply and demand in general, but at least in our study's framework it would not be a magical tool to resolve all issues because the climate policy (carbon price) is implemented globally. 


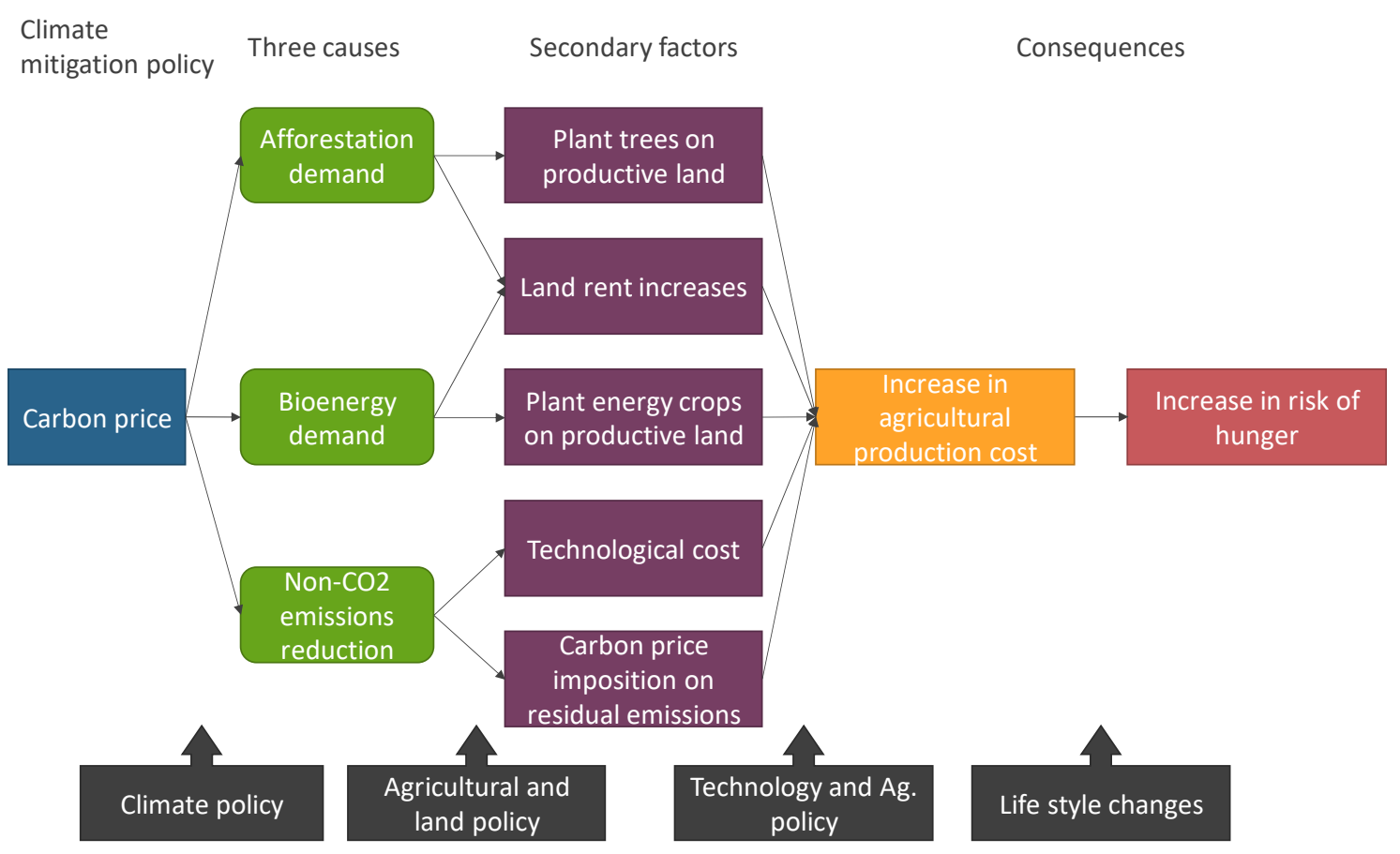

Figure 5. Summary of the three factors and effects on agricultural production cost and food security.

Other than the above discussion points, there should be some more arguments. First, the model uncertainty was not so small to indicate that the conclusion is always hold with any models in this study and this model variation comes from several factors. One is the way how to implement emissions reduction measures. For example, the models that show relatively high afforestation effects are AIM, GCAM and MAGNET, which explicit have land rent representation that may be related to the outcome. As reported earlier, land rent is currently relatively cheap, and carbon pricing on carbon sink would drastically affect. In contrast, GLOBIOM has no explicit land rent representation, and the cost increases in agricultural commodities would be caused by cropland shift from high to low productivity area. These differences would be eventually crucial. Since the structure quite differs across models (at least partial equilibrium models and general equilibrium models), it would be difficult to completely harmonize the way of implementation of mitigation measures and the model ranges would not be narrowed even if we put much efforts on that.

Second, in this study, we purely focused on agricultural and food security aspects, but there must be side-effects of afforestation on ecosystem (e.g. biodiversity). If forest area is newly expanded and revert to the natural forest land using such as native tree species, that would have additional environmental co-benefit in regenerating habitat of the lives ${ }^{43}$. In contrast, if the afforestation purely aims to sequestrate carbon from the atmosphere, the tree species for that purpose might be transplanted 
from elsewhere, which would not be attractive for the native species. Still, the land productivity of carbon sequestration is crucial as discussed earlier, if the afforestation purely aims to take the carbon from the atmosphere, the tree species to be chosen would be not the natural vegetation, and thus the concerns for the ecosystem would remain. Moreover, nitrogen pollution, water consumption can change from the climate change mitigation ${ }^{44,45,46}$ and comprehensive environmental assessment would allow us to see different implications.

\section{Method}

\section{Overall methodology}

We carried out a scenario analysis to decompose afforestation, bioenergy and non-CO2 effects on agricultural market and food security. Overall research framework is shown in Supplementary Figure 1. Six state-of-the-art global agricultural economic or integrated assessment models, which sufficiently represent agricultural sectors, and land use to assess the interaction between climate mitigation and food security, are applied for this scenario exercise. Global economic models compute the agricultural consumptions, production, land-use area and associated emissions by crops and livestock as well as forestry. Food consumption is then fed into hunger tool which computes individual countries' food consumption distribution and population at risk of hunger. To identify the magnitude of three causes on agricultural market, we developed a sensitivity scenario protocol that systematically switching on/off the mitigation options. Here we describe 1) scenario definition and protocol, 2) a brief model overview for each agricultural model (a summary is in Supplementary Table 2), and 3) hunger tool description.

\section{Scenarios and experiment design}

310 We developed a set of scenarios with combination of three socio-economic conditions and one mitigation policy scenarios (and one baseline scenario) that are consistent with $2{ }^{\circ} \mathrm{C}$ goal stated in the Paris Agreement or equivalent to RCP2.6 level emissions reduction ${ }^{47}$. For the socio-economic assumptions, we used three SSPs from the internationally developed SSP framework designed to conduct cross-sectoral assessments of climate change impact, adaptation, and mitigation ${ }^{26}$. The SSPs are representative future scenarios, which includes both qualitative and quantitative information in terms of challenges in mitigation and adaptation to climate change. In this study, we used three SSP scenarios from the SSP framework, i.e., "sustainability" (SSP1) ${ }^{23}$, "middle of the road" (SSP2) ${ }^{48}$, and "regional rivalry pathways" (SSP3) $)^{18}$ to address the uncertainty of socio-economic conditions.

To isolate the effect of each land-based mitigation options (afforestation, bioenergy, and non- $\mathrm{CO}_{2}$ emissions reduction + carbon price imposition), we used a recently developed ${ }^{49,50}$ and widely applied methodology ${ }^{27}$ that identifies the individual effects of an input factor with a limited number of model experiments even in a complex system. In general, we could classify the mitigation options into four 
categories, i.e., afforestation, bioenergy, non- $\mathrm{CO}_{2}$ pricing, and other (tax on non-AgLU sectors). The first three are land-related mitigation options and are the focus of this study. Therefore, we designed three scenarios with each applying only one of the land-related mitigation options, and one scenario that apply all three options simultaneously, as shown in Supplementary Table 3 (for the models with non-agricultural sectoral emission (e.g., energy sectors), including AIM, GCAM, and FARM, since it is difficult to turn off these mitigation options, tax on non-agricultural sectoral emission was also applied in these four scenarios).

We have also run sensitivity scenarios for the models with enough modeling ability, where most mitigation measures are available and only one is switched off with AIM and GLOBIOM which sufficiently represent all agricultural activities and GHG emissions(Supplementary Table 2 and Supplementary Table 3). This exercise could enhance the robustness of our decomposition methodology, which is similar to the way carried out by other climate change literatures ${ }^{27,51}$ (Supplementary Table 4). For all mitigation scenarios, a global uniform carbon tax (except for FARM, which applies an endogenous carbon price??) was imposed in these mitigation scenarios ${ }^{48}$, as shown in Supplementary Figure 2. All model submission status is shown in Supplementary Table 5.

Regarding non-agricultural sectors interactions, models without representation of nonagricultural sectors (CAPRI, GLOBIOM, IMAGE-MAGNET) can be assessed by directly comparing baseline and mitigation scenarios. For the models with representation of non-agricultural sectoral sectors (AIM, GCAM, FARM), we need to further identify the effect of non-agricultural activity (e.g. macro-economic feedback associated with energy system changes) and thus we run all mitigation measures off scenarios (Supplementary Table 6). The final result presented was the average of scenario sets and decomposition method, which aimed to account for the uncertainty in modeling capacity and

\section{Model description}

$348 \mathbf{A I M} / \mathbf{H u b}^{\mathbf{1 8}}$, which is formerly named as AIM/CGE, is a one-year-step recursive-type dynamic general equilibrium model that covers all regions of the world. The AIM/Hub model includes 17 regions and 42 industrial classifications. For appropriate assessment of bioenergy and land use competition, agricultural sectors are also highly disaggregated ${ }^{52}$. Details of the model structure and mathematical formulae are described by Fujimori, Masui ${ }^{53}$. The production sectors are assumed to maximize profits under multi-nested constant elasticity substitution (CES) functions and each input price. Energy transformation sectors input energy and value-added are fixed coefficients of output. They are treated in this manner to deal with energy conversion efficiency appropriately in the energy transformation sectors. Power generation values from several energy sources are combined with a Logit function. This functional form was used to ensure energy balance because the CES function does not guarantee an energy balance. Household expenditures on each commodity are described by a linear 
expenditure system function. The parameters adopted in the linear expenditure system function are recursively updated by income elasticity assumptions ${ }^{24}$. Land use is determined by Logit selection ${ }^{54}$.

361 Land use change emissions are derived from the forest area change relative to the previous year 362 multiplied by the carbon stock density, which is differentiated by AEZs (Global Agro-Ecological 363 Zones). Non-energy-related emissions other than land use change emissions are assumed to be in proportion to the level of each activity (such as output). $\mathrm{CH}_{4}$ has a range of sources, mainly the rice production, livestock, fossil fuel mining, and waste management sectors. $\mathrm{N}_{2} \mathrm{O}$ is emitted as a result of fertilizer application and livestock manure management and by the chemical industry.

MAGNET-IMAGE is the combination of the agro-economic model MAGNET ${ }^{55}$ and the integrated assessment model $\mathrm{IMAGE}^{56}$. MAGNET is a multi-regional, multi-sectoral, applied general equilibrium model ${ }^{56}$. based on neo-classical microeconomic theory which is an extension of the standard GTAP model. The core of MAGNET is an input-output model, which links industries in value added chains from primary goods to final goods and services for consumption. Input and output prices are endogenously determined by the markets to achieve supply and demand equilibrium. The agricultural sector is represented in high detail compared to standard CGE models. Developments in productivity are driven by a combination of assumptions on autonomous technological change provided by IMAGE and by economic processes as modelled by MAGNET (i.e. substitution between production factors). Land is modelled as an explicit production factor described by a land supply curve, constructed with land availability data provided by IMAGE.

IMAGE is a comprehensive integrated assessment framework, modelling interactions between the human and natural systems ${ }^{56}$. The framework comprises a number of sub-models describing land use, agricultural economy, the energy system, natural vegetation, hydrology, and the climate system. In this study specifically the land component is applied which represents land use, crop production, afforestation and the carbon cycle spatially explicitly at 5 arc-minutes resolution. emissions from agricultural is based on Lucas et $\mathrm{al}^{57}$. The residual emissions are taxed in MAGNET. The costs of technical mitigation are also implemented as part of the tax. The level of avoided deforestation and afforestation policy is determined in IMAGE through the climate policy model FAIR-SimCAP that makes a cost-effectiveness assessment of these mitigation options compared to other options energy and industry sectors ${ }^{16}$. The policy measures are subsequently implemented in MAGNET through reduced land availability. 
GLOBIOM represents the competition between different land-use based activities. It includes a detailed representation of the agricultural, forestry and bio-energy sector, which allows for the inclusion of detailed grid-cell information on biophysical constraints and technological costs, as well as a rich set of environmental parameters, incl. comprehensive AFOLU (agriculture, forestry and other land use) GHG emission accounts and irrigation water use. For spatially explicit projections of the change in afforestation, deforestation, forest management, and their related $\mathrm{CO}_{2}$ emissions, GLOBIOM is coupled with the G4M (Global FORest Model) model ${ }^{59}$. As outputs, G4M provides estimates of forest area change, carbon uptake and release by forests, and supply of biomass for bioenergy and timber.

GCAM integrated assessment model links modules of the economy, the energy system, the agriculture and land-use system, and the climate ${ }^{60,61,62}$. The agriculture and land-use component determines supply, demand, and prices for crop, animal and forestry production and bioenergy based on expected profitability. In doing so, the model determines land allocation across these categories, as well as pastureland, grassland, shrubland, and noncommercial forestland. The agriculture and land-use component of GCAM is fully-coupled with the energy, economic, and climate modules within GCAM; that is, all four components are solved simultaneously. In the version of GCAM used in this study, bioenergy provides the primary linkage between the agriculture and land-use component and the energy component, with bioenergy produced by the land system and consumed by the energy system. The agriculture and land component is coupled to the energy economy through bioenergy and carbon prices. Carbon prices are imposed iteratively until the prescribed climate target is reached. The carbon prices influence the cost of fossil fuel energy technologies, and the profitability of land cover options. In particular, GCAM assumes the carbon price is applied to carbon stocks held in the terrestrial system, incentivizing land owners to increase these stocks. As a result, strong incentives exist to expand carbon stocks under a climate policy, resulting in significant afforestation. The agriculture and land-use component is connected to the climate through emissions $\left(\mathrm{CO}_{2}\right.$ and non- $\left.\mathrm{CO}_{2}\right)$, which are produced by the land system and passed into the climate system to calculate concentrations, radiative forcings, and other climate indicators.

CAPRI (Common Agricultural Policy Regionalised Impact) modelling system is an economic largescale, comparative-static, partial equilibrium model focusing on agriculture and the primary processing sectors (www.capri-model.org). CAPRI comprises two interacting modules, linking a set of mathematical programming models of EU regional agricultural supply to a spatial multicommodity model for global agri-food markets. The regional EU supply models depict a profit maximizing behavior of representative farms for all EU NUTS 2 regions (i.e. the Nomenclature of territorial units for statistics is a hierarchical system developed by EUROSTAT for dividing up the economic territory 
of the EU), taking constraints related to land availability, nutrient balances for cropping and animal activities and policy restrictions into account. The market module consists of a spatial, non-stochastic global multi-commodity model for about 60 primary and processed agricultural products, covering 77 countries in 40 trading blocks. Bilateral trade flows and attached prices are modelled based on the Armington assumption of quality differentiation ${ }^{63}$. The behavioral functions in the market model represent supply and demand for primary agricultural and processed commodities (including human and feed consumption, biofuel use, import demand from multilateral trade relations), balancing constraints and agricultural market policy instruments (i.e. import tariffs, tariff rate quotas, producer and consumer support estimates, etc.) . With regard to GHG accounting, CAPRI calculates EU agricultural GHG emissions for the most important nitrous oxide and methane emission sources based on the inputs and outputs of agricultural production activities, following to a large extent the 2006 IPCC guidelines. It also includes specific technical and management-based GHG mitigation options for EU agriculture into account. GHG emissions for the rest of the world are estimated on a commodity basis in the market model ${ }^{64}$

FARM (Future Agricultural Resources Model) is a global computable general equilibrium (CGE) model with 13 world regions that operates in 5-year steps from 2011 to $2101^{65}$. Data requirements include a base-year social accounting matrix from the Global Trade Analysis Project (GTAP) at Purdue University, energy balances from the International Energy Agency, land use from the Food and Agriculture Organization (FAO) of the United Nations, and agricultural production from FAO. FARM has been extended in many ways beyond the "GTAP in GAMS" model described in Lanz and Rutherford (2016) ${ }^{66}$ : conversion from comparative-static to a recursive-dynamic framework; conversion of the consumer demand system from constant-elasticity-of-substitution (CES) to the Linear Expenditure System (LES); allowing for joint products in production functions; introduction of land classes for agricultural and forestry production; and introduction of electricity-generating technologies. Two markets are important for bioelectricity: the market for land and the market for electricity. Bioelectricity must compete against crops, pasture, and forest for land, and must also compete for a share of electricity generation. Land shifts among crops, pasture, and forests in response to population growth, dietary preference, changes in agricultural productivity, and policies such as a renewable portfolio standard or a carbon tax. Land competition is based on the land rent for each competing use: land use is adjusted within agroecological zones until rents at the margin are equal. Carbon dioxide capture and storage is available for electricity generated from fossil fuels and from bioelectricity.

\section{The estimation method of number of people at risk of hunger}

In principle, the risk of hunger can be calculated by referring to the mean calorie consumption, 
which is the same approach as in AIM and IMAGE. The narrow definition of undernourishment or hunger is a state of energy (calorie) deprivation lasting over one year; this does not include the shortlived effects of temporary crises ${ }^{67,68}$. Furthermore, this does not include inadequate intake of other essential nutrients ${ }^{67}$. The population at risk of hunger is a proportion of the total population and is calculated using Eq. 1.

$$
\text { Risk }_{t}=P O P_{t} \cdot P o U_{t}
$$

where,

$t:$ year

Risk $_{t}$ : population at risk of hunger in year $t$ [person]

$P O P_{t}$ :population in year $t$ [person]

$P_{o} U_{t}$ :proportion of the population at risk of hunger in year $t[-]$

According to the Food and Agriculture Organization (FAO) methodology ${ }^{69}$, the proportion of the population at risk of hunger is defined using Eqs. 2 to 4. With the FAO methodology, the proportion is calculated using three parameters: the mean food calorie consumption per person per day ( $c a l)$, the mean minimum dietary energy requirement $(M)$, and the coefficient of variation of the food distribution of the dietary energy consumption in a country $(\mathrm{CV})$. The food distribution within a country is assumed to follow a log normal distribution. The proportion of the population under the mean minimum dietary energy requirement $(M)$ is defined as the proportion of the population at risk of hunger. The log normal distribution has two parameters, the mean $\mu_{t}$ and the variance $\sigma_{t}$, as in Eq. 2. The parameters $\mu_{t}$, and $\sigma_{t}$ can be represented using the mean food calorie consumption per person per day ( $\mathrm{cal}$ ) and the coefficient of variation of the domestic distribution of dietary energy consumption $(\mathrm{CV})$ as Eqs. 3 and 4.

Each IAM reports the mean food calorie consumption per person per day ( $c a l)$. We standardize the base year calorie consumption to what FAO reports and take the change ratio of each year to the base year for IAMs. We then compute the standardized calorie consumption to make a consistent number for those at risk of hunger. In this process, since the IAM's are regionally aggregated values, they are downscaled to the individual country level by taking the base year value reported FAO and future change ratio from IAMs. The $C V$ is an indicator of food security observed in a household survey conducted by the FAO. It ranges from 0 to 1 . FAO country data for $\mathrm{CV}$ are weighted on the basis of population data in the base year and aggregated to regional classification to obtain the CV of aggregated regions. The $\mathrm{CV}$ is changed over time with the consideration of income growth dynamics as presented in Hasegawa et al. ${ }^{24}$. Note that there is an assumption that the future $\mathrm{CV}$ changes of each region is based on the current regional value.

$$
\operatorname{PoU}_{t}=\Phi\left(\log M_{t}-\mu\left(c a l_{t}, \sigma_{t}\right) / \sigma_{t}\right)
$$




$$
\sigma_{t}=\left[\log _{e}\left(C V^{2}+1\right)\right]^{0.5}
$$

where,

$M_{t}$ : mean minimum dietary energy requirement in year $t$

$C V_{t}$ : coefficient of variation of the inter-national distribution of dietary energy consumption in year $t$

$\Phi$ : standard normal cumulative distribution

$c a l_{t}$ :mean food calorie intake per person per day in year $t$

499

\section{References \\ References}

where,

$i$ : age group;

$j$ : sex; year;

The mean minimum dietary energy requirement $(M)$ is calculated for each year and country by using the mean minimum dietary energy requirement in the base year at the country level ${ }^{70,71,72}$ and an adjustment coefficient for the minimum energy requirements per person in different age and sex groups ${ }^{71}$ and the population of each age and sex group in each year ${ }^{72}$, as in Eqs. 5 and 6.

$$
M_{t}=\text { Mbase } \cdot \frac{M E R_{t}}{\text { MERbase }}
$$

$$
M E R_{t}=\frac{\sum_{i, j} R M E R_{i, j} \cdot \text { Pclass }_{i, j, t}}{\sum_{i, j} \text { Pclass }_{i, j, t}}
$$

Mbase: mean minimum dietary energy requirement per person in the base year;

$M E R_{t}$ : Mean adjustment coefficient of minimum energy requirements per person in year $t$;

$M E R_{\text {base }}$ : Mean adjustment coefficient of the minimum energy requirements per person in the base

$R M E R_{i, j}$ : Adjustment coefficient for the minimum energy requirements per person of age $i$ and sex $j$; Pclass $_{i . j, t}$ : population of age $i$ and $\operatorname{sex} j$ in year $t$.

\section{Data availability}

Model output data is available at http://doi.org/10.5281/zenodo.4319606.

\section{Author contributions}


1. Blanco G, Gerlagh R, Suh S, Barrett J, de Coninck HC, Morejon CD, et al. Drivers, trends and mitigation. Cambridge University Press: Cambridge, UK and New York,, 2014.

2. Fuss S, Lamb WF, Callaghan MW, Hilaire J, Creutzig F, Amann T, et al. Negative emissionsPart 2: Costs, potentials and side effects. Environmental Research Letters 2018, 13(6): 063002.

3. Popp A, Lotze-Campen H, Bodirsky B. Food consumption, diet shifts and associated non-CO2 greenhouse gases from agricultural production. Global Environmental Change 2010, 20(3): 451-

9. Gambhir A, Butnar I, Li P-H, Smith P, Strachan N. A Review of Criticisms of Integrated Assessment Models and Proposed Approaches to Address These, through the Lens of BECCS.

10. Gough C, Garcia-Freites S, Jones C, Mander S, Moore B, Pereira C, et al. Challenges to the use 
560 12. Hasegawa T, Sands RD, Brunelle T, Cui Y, Frank S, Fujimori S, et al. Food security under high bioenergy demand toward long-term climate goals. Climatic Change 2020.

13. Fujimori S, Hasegawa T, Krey V, Riahi K, Bertram C, Bodirsky BL, et al. A multi-model

14. Fujimori S, Hasegawa T, Rogelj J, Su X, Havlik P, Krey V, et al. Inclusive climate change mitigation and food security policy under $1.5^{\circ} \mathrm{C}$ climate goal. Environmental Research Letters

15. Frank S, Havlík P, Stehfest E, van Meijl H, Witzke P, Pérez-Domínguez I, et al. Agricultural non-

16. Doelman JC, Stehfest E, van Vuuren DP, Tabeau A, Hof AF, Braakhekke MC, et al. Afforestation

17. Humpenöder F, Popp A, Dietrich JP, Klein D, Lotze-Campen H, Bonsch M, et al. Investigating

21. Calvin K, Bond-Lamberty B, Clarke L, Edmonds J, Eom J, Hartin C, et al. The SSP4: A world of 
22. Fricko O, Havlik P, Rogelj J, Klimont Z, Gusti M, Johnson N, et al. The marker quantification of

30. Harmsen M, van Vuuren DP, Bodirsky BL, Chateau J, Durand-Lasserve O, Drouet L, et al. The role of methane in future climate strategies: mitigation potentials and climate impacts. Climatic

24. Hasegawa T, Fujimori S, Takahashi K, Masui T. Scenarios for the risk of hunger in the twentyfirst century using Shared Socioeconomic Pathways. Environmental Research Letters 2015, 10(1): 014010 .

25. Hasegawa T, Fujimori S, Takahashi K, Yokohata T, Masui T. Economic implications of climate change impacts on human health through undernourishment. Climatic Change 2016, 136: 1-14.

26. Riahi K, van Vuuren DP, Kriegler E, Edmonds J, O'Neill BC, Fujimori S, et al. The Shared Socioeconomic Pathways and their energy, land use, and greenhouse gas emissions implications: An overview. Global Environmental Change-Human and Policy Dimensions 2017, 42: 153-168.

27. Stehfest E, van Zeist W-J, Valin H, Havlik P, Popp A, Kyle P, et al. Key determinants of global land-use projections. Nature Communications 2019, 10(1): 2166.

28. Hasegawa T, Fujimori S, Takahashi K, Masui T. Scenarios for the risk of hunger in the twentyfirst century using Shared Socioeconomic Pathways. Environmental Research Letters 2015, 10(1).

29. von Lampe M, Willenbockel D, Ahammad H, Blanc E, Cai Y, Calvin K, et al. Why do global longterm scenarios for agriculture differ? An overview of the AgMIP Global Economic Model Intercomparison. Agricultural Economics 2014, 45(1): 3-20.

Change 2019.

31. Gernaat DEHJ, Calvin K, Lucas PL, Luderer G, Otto SAC, Rao S, et al. Understanding the 
contribution of non-carbon dioxide gases in deep mitigation scenarios. Global Environmental Change 2015, 33(0): 142-153.

32. Daioglou V, Doelman JC, Wicke B, Faaij A, van Vuuren DP. Integrated assessment of biomass supply and demand in climate change mitigation scenarios. Global Environmental Change 2019, 54: $88-101$.

33. Popp A, Calvin K, Fujimori S, Havlik P, Humpenoeder F, Stehfest E, et al. Land-use futures in the shared socio-economic pathways. Global Environmental Change-Human and Policy Dimensions 2017, 42: 331-345.

34. Rogelj J, Meinshausen M, Schaeffer M, Knutti R, Riahi K. Impact of short-lived non-CO 2 mitigation on carbon budgets for stabilizing global warming. Environmental Research Letters 2015, 10(7): 075001.

35. Grubler A, Wilson C, Bento N, Boza-Kiss B, Krey V, McCollum DL, et al. A low energy demand scenario for meeting the $1.5^{\circ} \mathrm{C}$ target and sustainable development goals without negative emission technologies. Nature Energy 2018, 3(6): 515-527.

36. van Vuuren DP, Stehfest E, Gernaat DEHJ, van den Berg M, Bijl DL, de Boer HS, et al. Alternative pathways to the $1.5^{\circ} \mathrm{C}$ target reduce the need for negative emission technologies. Nature Climate Change 2018, 8(5): 391-397.

37. Wise M, Calvin K, Thomson A, Clarke L, Bond-Lamberty B, Sands R, et al. Implications of limiting CO2 concentrations for land use and energy. Science 2009, 324(5931): 1183-1186.

38. Calvin K, Wise M, Kyle P, Patel P, Clarke L, Edmonds J. Trade-offs of different land and bioenergy policies on the path to achieving climate targets. Climatic Change 2014, 123(3): 691-704.

39. Fujimori S, Hasegawa T, Oshiro K. An assessment of the potential of using carbon tax revenue to tackle poverty. Environmental Research Letters 2020, 15(11): 114063.

40. Springmann M, Mason-D/'Croz D, Robinson S, Wiebe K, Godfray HCJ, Rayner M, et al. Mitigation potential and global health impacts from emissions pricing of food commodities. Nature Clim Change 2017, 7(1): 69-74. 
41. Stehfest E, Bouwman L, Vuuren DP, Elzen MGJ, Eickhout B, Kabat P. Climate benefits of changing diet. Climatic Change 2009, 95(1-2): 83-102.

42. Hasegawa T, Havlík P, Frank S, Palazzo A, Valin H. Tackling food consumption inequality to fight hunger without pressuring the environment. Nature Sustainability 2019, 2(9): 826-833.

43. Leclère D, Obersteiner M, Barrett M, Butchart SHM, Chaudhary A, De Palma A, et al. Bending the curve of terrestrial biodiversity needs an integrated strategy. Nature 2020.

44. Bodirsky BL, Popp A, Lotze-Campen H, Dietrich JP, Rolinski S, Weindl I, et al. Reactive nitrogen requirements to feed the world in 2050 and potential to mitigate nitrogen pollution. Nature Communications 2014, 5(1): 3858 .

45. Vitousek PM, Menge DNL, Reed SC, Cleveland CC. Biological nitrogen fixation: rates, patterns and ecological controls in terrestrial ecosystems. Philosophical Transactions of the Royal Society B: Biological Sciences 2013, 368(1621): 20130119.

46. Hejazi, Edmonds J, Clarke L, Kyle P, Davies E, Chaturvedi V, et al. Long-term global water projections using six socioeconomic scenarios in an integrated assessment modeling framework. Technological Forecasting and Social Change 2014, 81: 205-226.

47. van Vuuren DP, Stehfest E, den Elzen MGJ, Kram T, van Vliet J, Deetman S, et al. RCP2.6: exploring the possibility to keep global mean temperature increase below $2^{\circ} \mathrm{C}$. Climatic Change 2011, 109(1-2): 95-116.

48. Fricko O HPGM, Johnson N. The marker quantification of the Shared Socioeconomic Pathway 2: A middle-of-the-road scenario for the 21st century. Global Environmental Change 2017, 42: 251.

49. Borgonovo E. Sensitivity analysis with finite changes: An application to modified EOQ models. European Journal of Operational Research 2010, 200(1): 127-138.

50. Borgonovo E. A Methodology for Determining Interactions in Probabilistic Safety Assessment Models by Varying One Parameter at a Time. Risk Analysis 2010, 30(3): 385-399.

51. Marangoni G, Tavoni M, Bosetti V, Borgonovo E, Capros P, Fricko O, et al. Sensitivity of projected long-term CO2 emissions across the Shared Socioeconomic Pathways. Nature Climate 
52. Fujimori S, Hasegawa T, Masui T, Takahashi K. Land use representation in a global CGE model for long-term simulation: CET vs. logit functions. Food Security 2014, 6(5): 685-699.

53. Fujimori S, Masui T, Matsuoka Y. AIM/CGE [basic] manual: Center for Social and Environmental Systems Research, National Institute Environmental Studies; 2012. Report No.: 2012-01.

54. Fujimori S, Hasegawa T, Masui T, Takahashi K. Land use representation in a global CGE model for long-term simulation: CET vs. logit functions. Food Secur 2014, 6.

55. Woltjer GB, Kuiper MH. The MAGNET model: Module description. Wageningen: LEI Wageningen UR; 2014.

56. Stehfest E, van Vuuren D, Bouwman L, Kram T. Integrated assessment of global environmental change with IMAGE 3.0: Model description and policy applications. Netherlands Environmental Assessment Agency (PBL), 2014.

57. Lucas PL, van Vuuren DP, Olivier JGJ, den Elzen MGJ. Long-term reduction potential of nonCO2 greenhouse gases. Environmental Science \& Policy 2007, 10(2): 85-103.

58. Havlík P, Valin H, Herrero M, Obersteiner M, Schmid E, Rufino MC, et al. Climate change mitigation through livestock system transitions. Proceedings of the National Academy of Sciences 2014, 111(10): 3709-3714.

59. Kindermann GE, Obersteiner M, Rametsteiner E, McCallum I. Predicting the deforestation-trend under different carbon-prices. Carbon Balance and management 2006, 1(1): 15.

60. Kyle P, Luckow P, Calvin K, Emanuel W, Nathan M, Zhou Y. GCAM 3.0 Agriculture and Land Use: Data Sources and Methods: PACIFIC NORTHWEST NATIONAL LABORATORY; 2011.

61. Calvin K, Patel P, Clarke L, Asrar G, Bond-Lamberty B, Cui RY, et al. GCAM v5.1: representing the linkages between energy, water, land, climate, and economic systems. Geosci Model Dev 2019, 12(2): 677-698.

62. Wise M, Calvin K. GCAM 3.0 Agriculture and Land Use; Technical Description of Modeling 
Approach; 2011.

63. Armington SP. A Theory of Demand for Products Distinguished by Place of Production. Staff Papers 1969, 16(1): 159-178.

64. Domínguez IP, Fellmann T, Weiss F, Witzke P, Barreiro-Hurlé J, Himics M, et al. An economic

66. Lanz B, Rutherford TF. GTAPinGAMS: Multiregional and Small Open Economy Models. 2016

67. FAO. The State of Food Insecurity in the World 2012 Economic growth is necessary but not

68. EC-JRC/PBL. Emission Database for Global Atmospheric Research (EDGAR), release version

69. FAO. FAO Methodology for the measurement of food deprivation: updating the minimum dietary

70. FAO. Food security indicators. In: FAO, editor. Rome, Italy; 2013.

71. FAO/WHO. Energy and protein requirements. Geneva, Switzerland: FAO/WHO; 1973. 


\section{Figures}
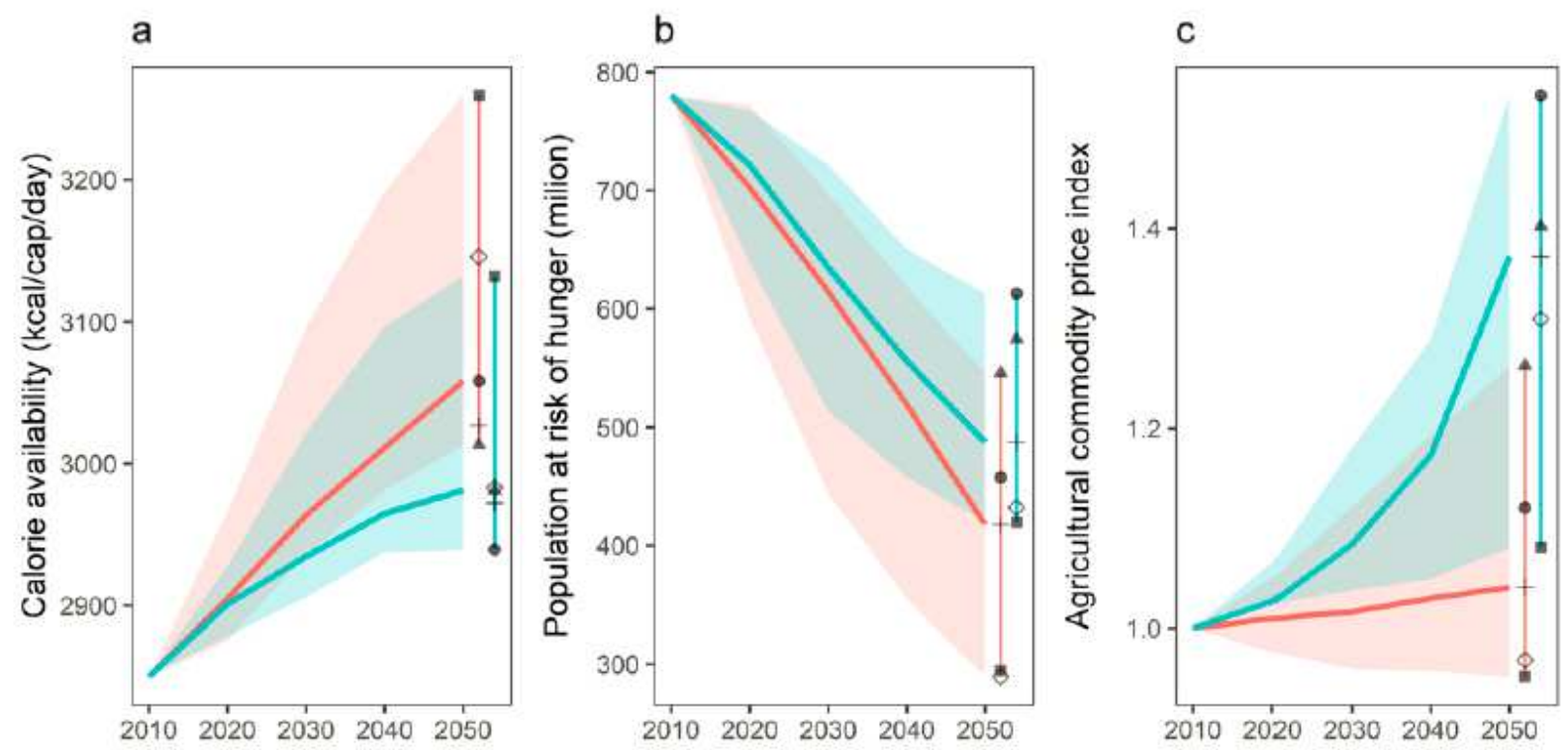

Climate policy

- Baseline

- Full mitigation
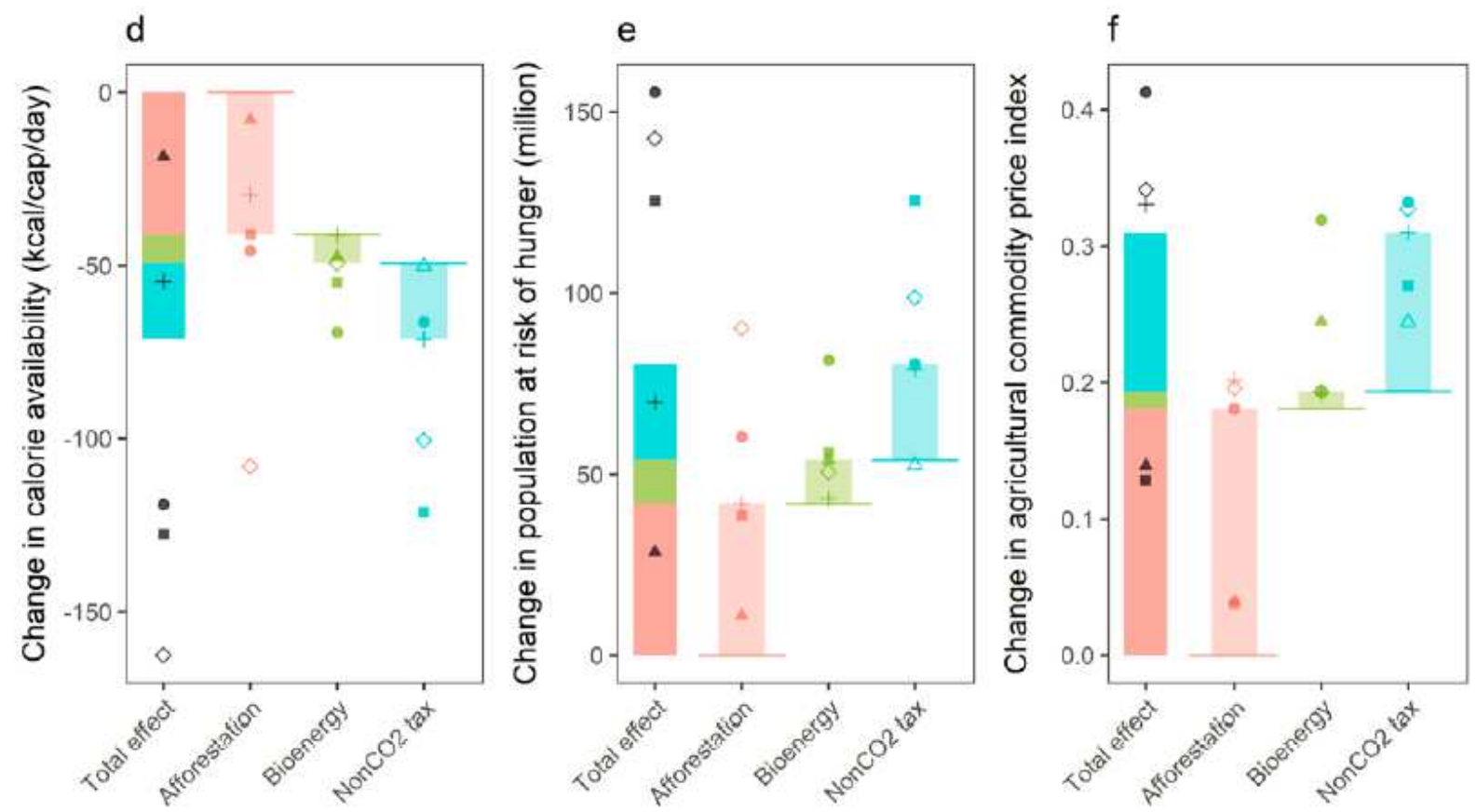

Model

- AIM/Hub

$\triangle$ CAPRI

- FARM

+ GCAM

- GLOBIOM

○ MAGNET-IMAGE

Component

Afforestation

Bioenergy

NonCO2 tax

\section{Figure 1}

Calorie availability (a), population at risk of hunger (b), and agricultural commodity price (c) in baseline and mitigation (full) scenarios, and the effects of each land-based mitigation measures on their change (def) for SSP2 (results based on four models with complete scenarios were shown in Supplementary Figure 5) 

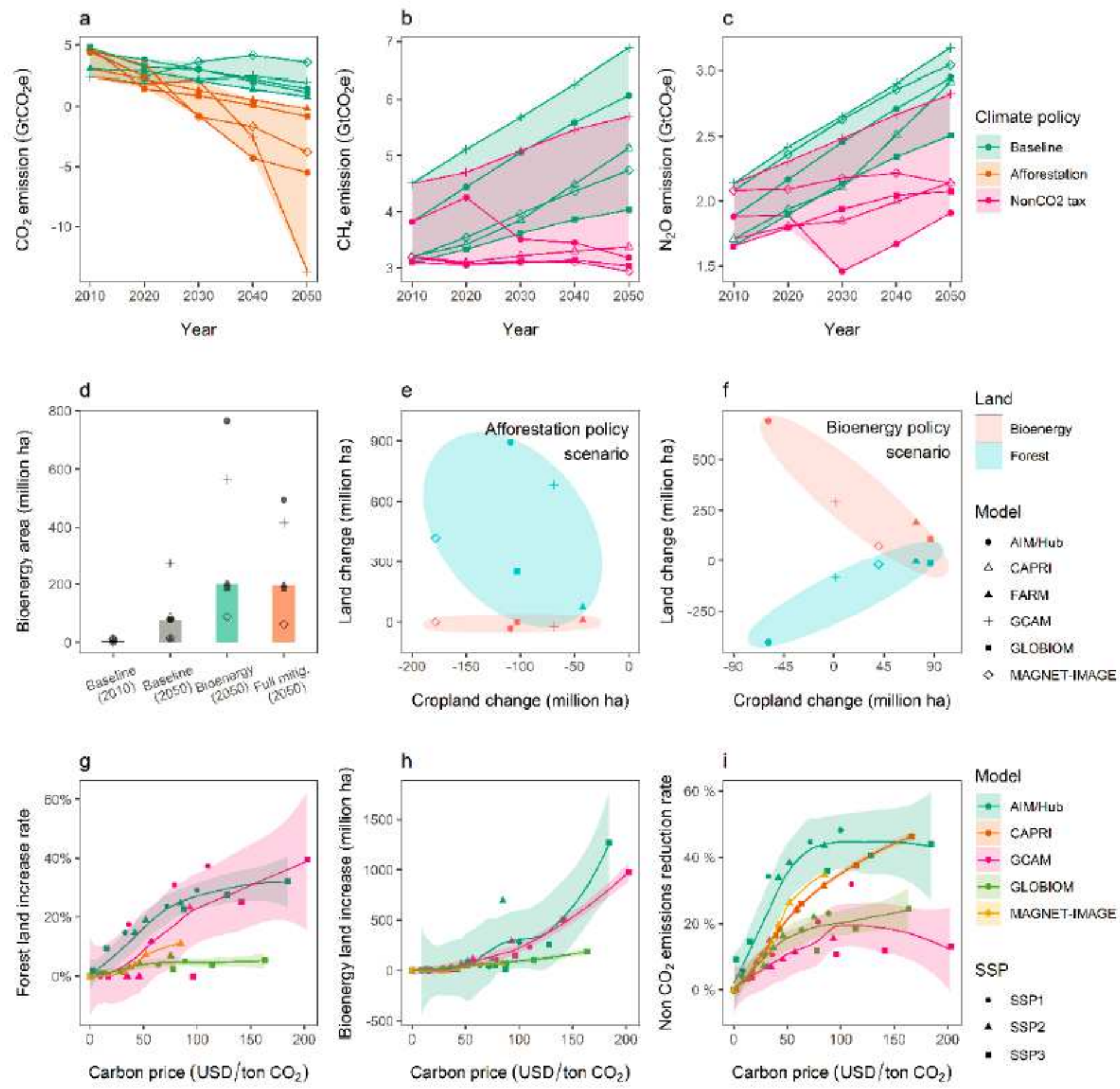

Figure 2

Main drivers of mitigation effects for SSP2. Panel ab and c present $\mathrm{CO} 2, \mathrm{CH} 4$ and N2O emissions from AFOLU sector. Panel $d$ shows bioenergy land in each scenario. Panel e and $f$ illustrate the relationship between cropland area, and bioenergy and forest area changes. Panel ghi show the relationship between carbon price and forest area, bioenergy area and non-CO2 emissions reduction rates (Non-CO2 emissions is CO2 equivalent value using GWP2100 in AR5). 
a

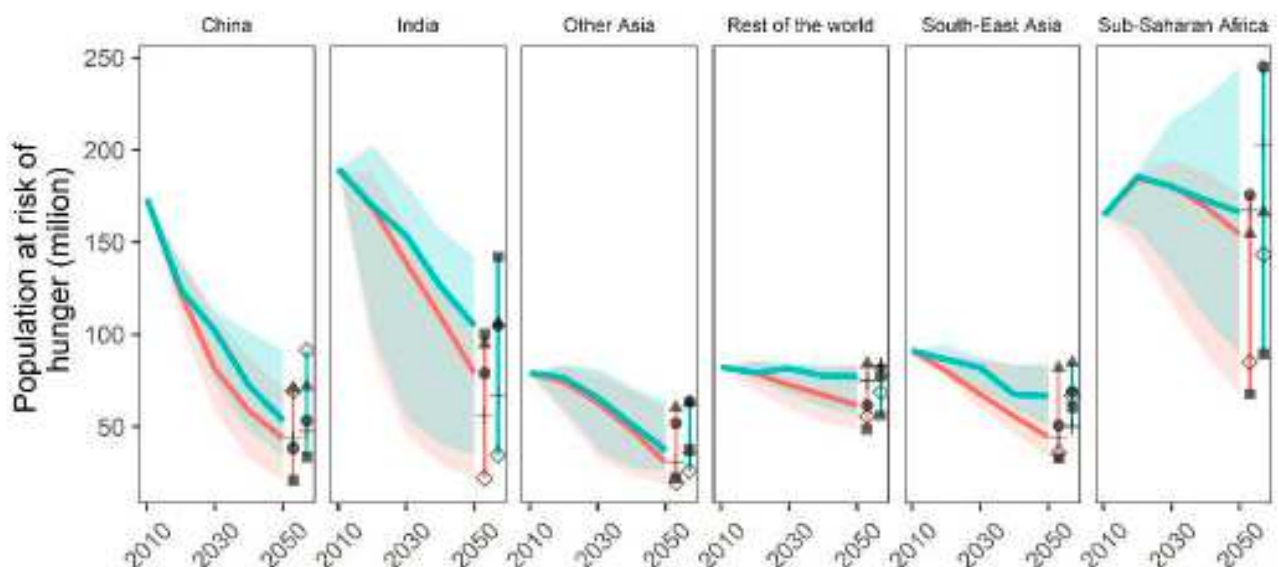

Climate policy

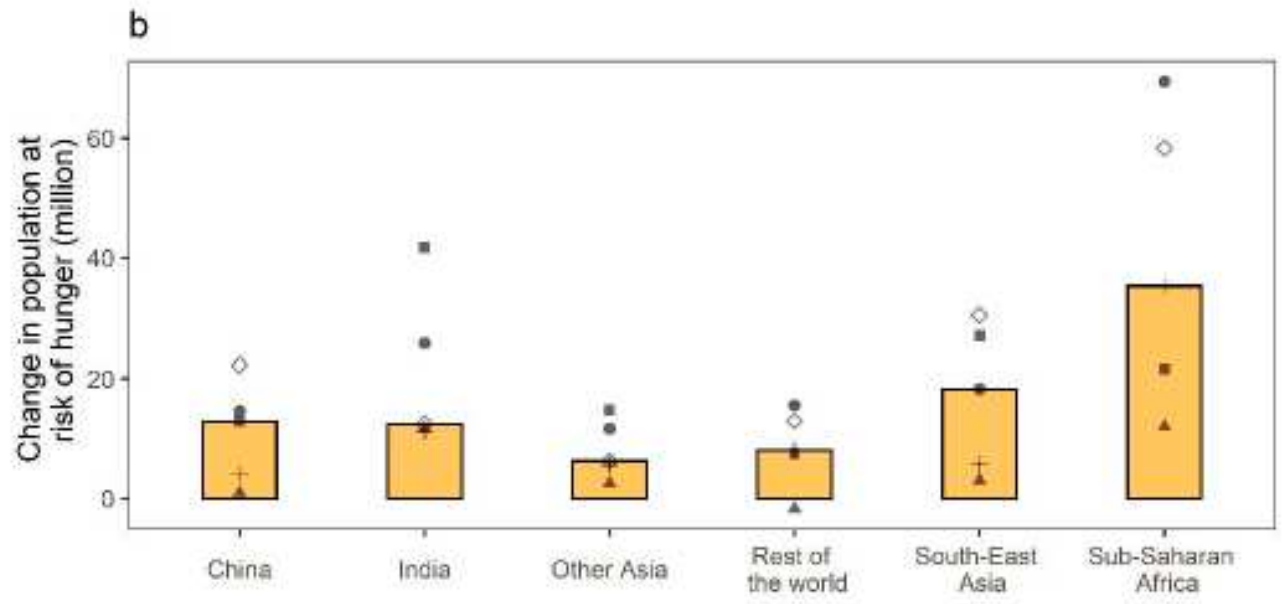

- Baseline

- Full mitigation

Model

- AlM/Hub

- farm

+ GCAMA

- GLOBIOM

$\checkmark$ MAGNet-IMAGE

\section{Component}

Afforestation

Bioenergy

NonCO2 tax
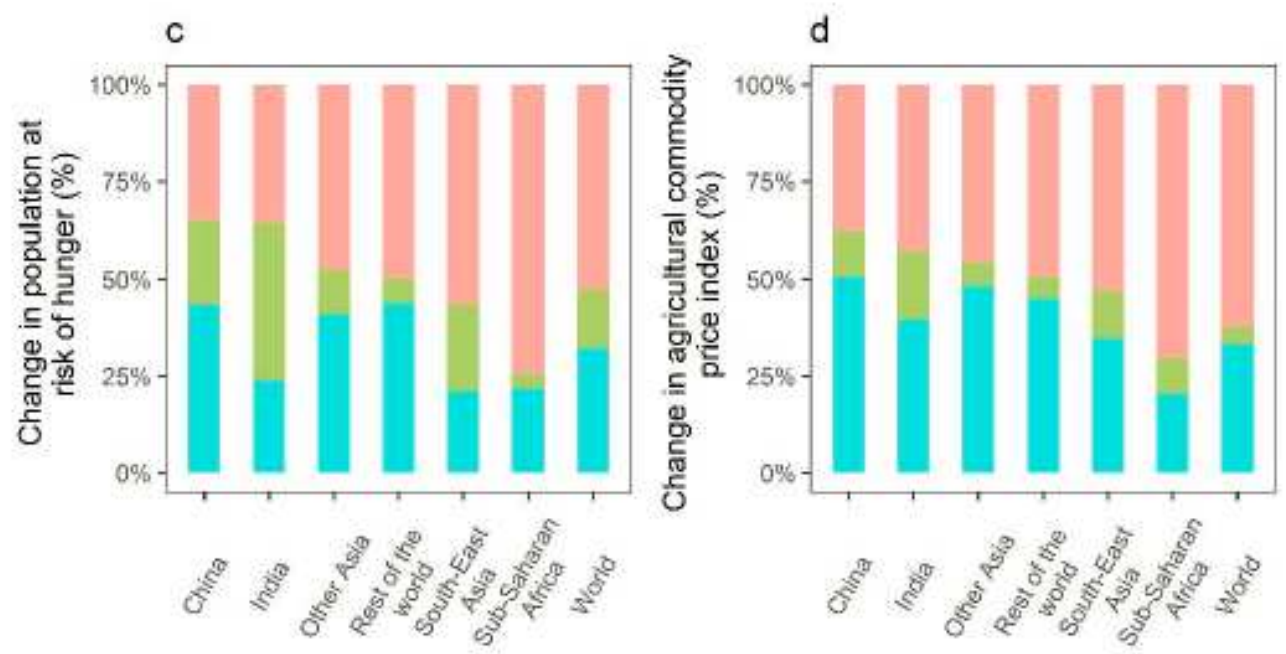

\section{Figure 3}

Regional effects of each land-based mitigation measures on risk of hunger and food price for SSP2. panel a shows the population at risk of hunger over the period by regions and panel $b$ shows changes in risk of hunger of mitigation scenario relative to baseline scenario. Panel cd show percentage share for each cause of changes in risk of hunger and agricultural price index. (see Supplementary Table 1 for regional definition) 
a
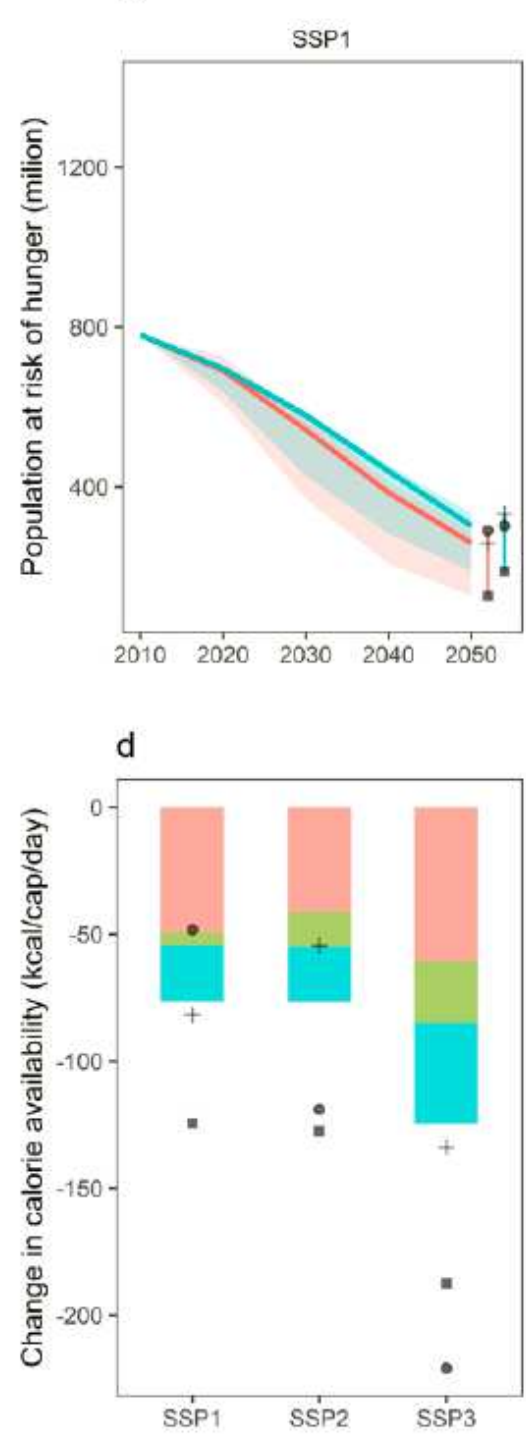

b
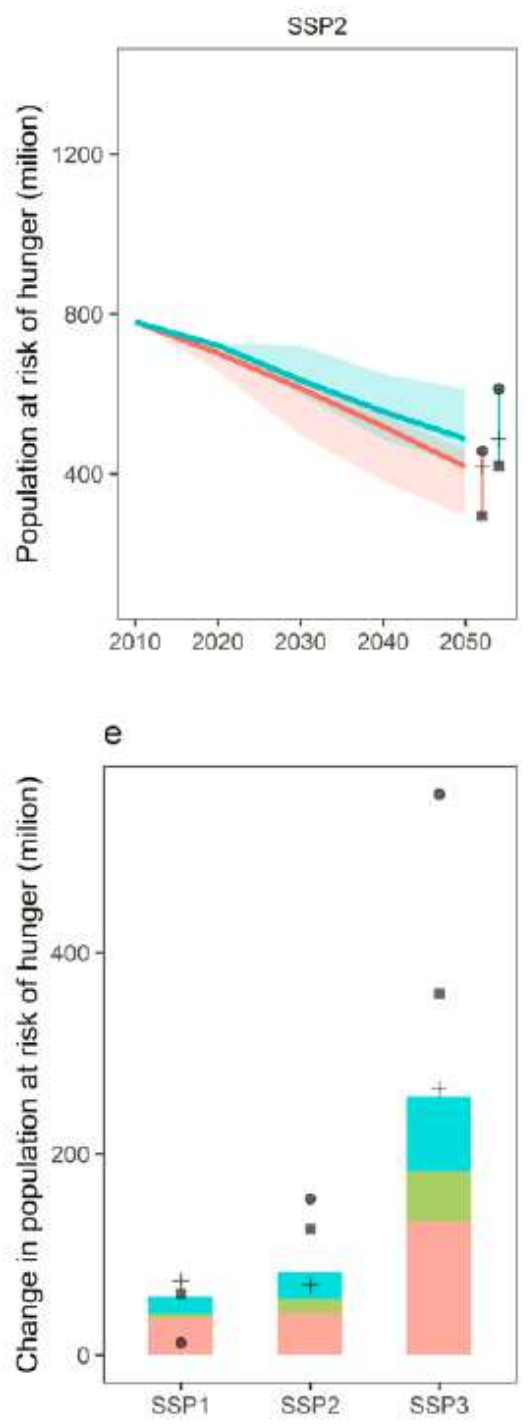

C
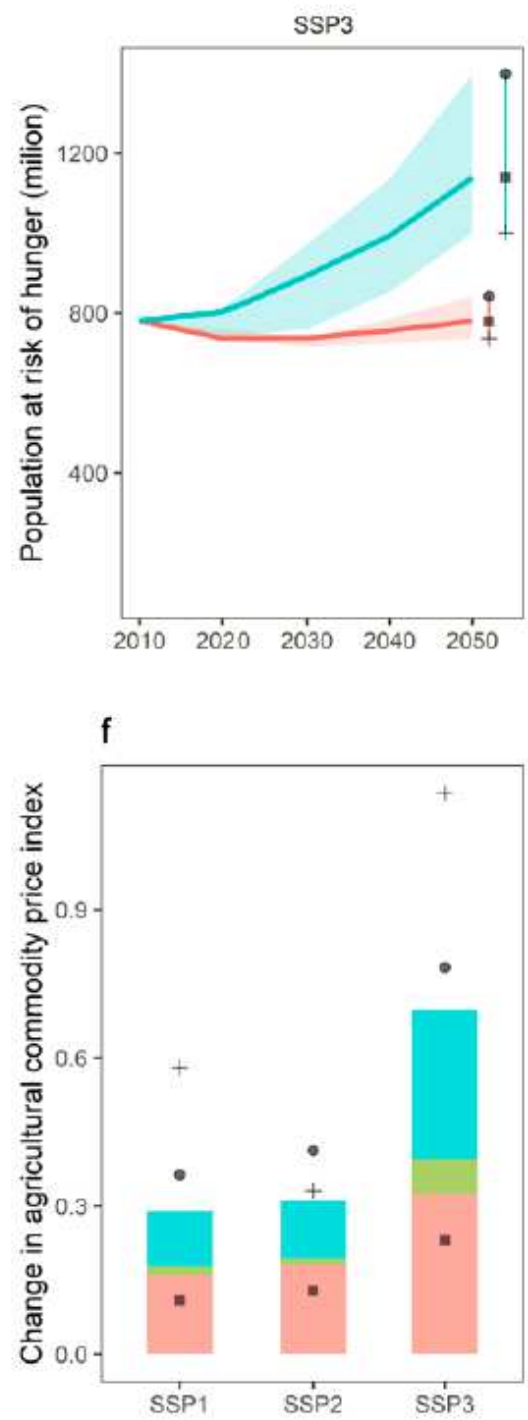

Climate policy

- Baseline Full mitigation

\section{Model}

- AlM/Hub

+ GCAM

- GLOBIOM

\section{Component}

Afforestation Bioenergy NonCO2 tax

\section{Figure 4}

SSP variations in global population at risk of hunger (abc) and change in food consumption, population at risk of hunger and agricultural price index in three SSPs in 2050 (def). 


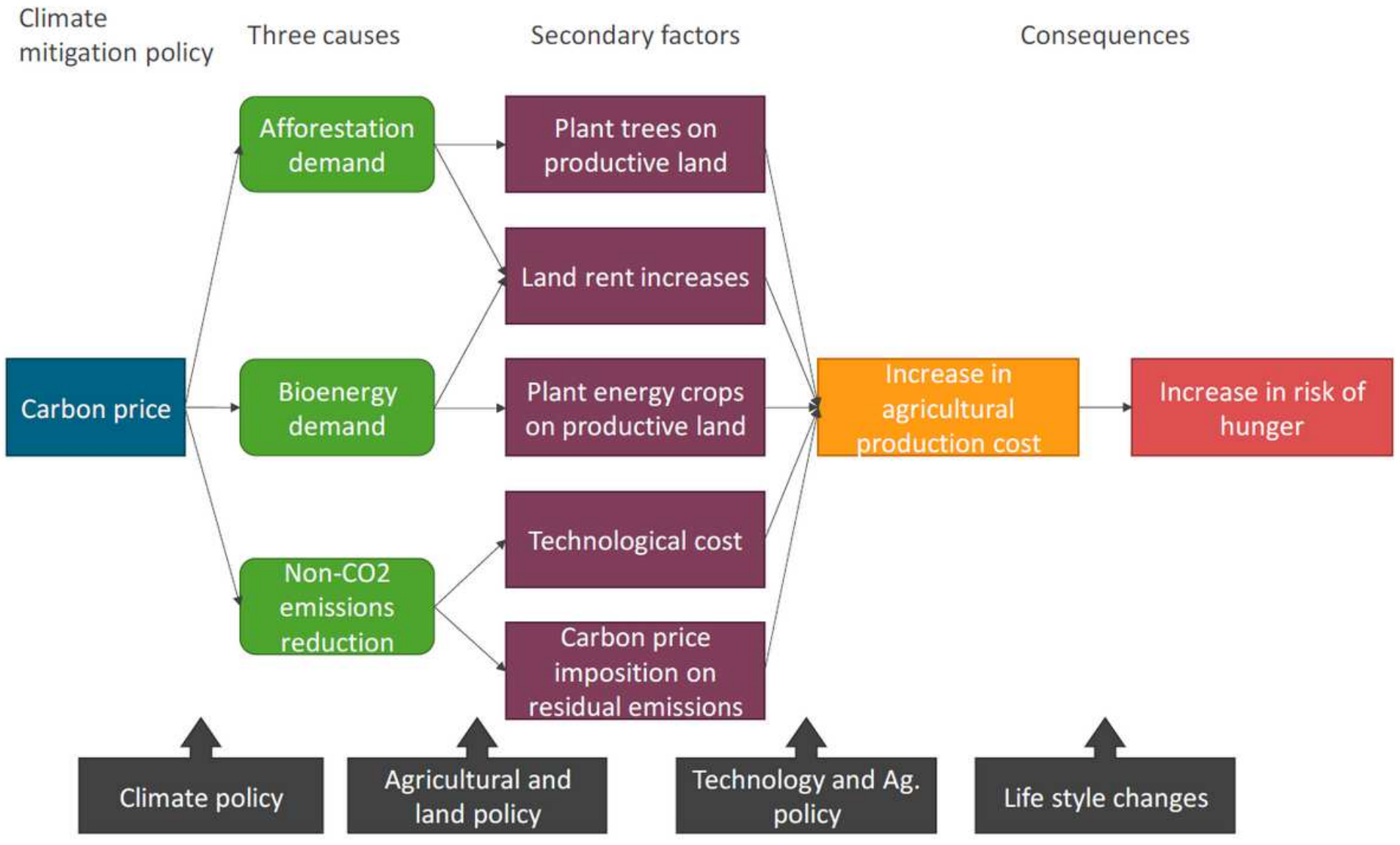

\section{Figure 5}

Summary of the three factors and effects on agricultural production cost and food security.

\section{Supplementary Files}

This is a list of supplementary files associated with this preprint. Click to download.

- SI.pdf 